\title{
O impacto do diagnóstico do HIV na gravidez ou pós-parto e seus efeitos na vida das mulheres: revisão integrativa de literatura
}

The impact of HIV diagnosis on pregnancy or post birth and its effects on women's life: integrativeliterature review

El impacto del diagnóstico del HIV enelembarazo o post nascimiento y sus efectosenla vida de lasmujeres: revisión integrativa de la literatura

Maria Almerice Espíndula da Silva Cavalcante ORCID: https://orcid.org/0000-0003-1735-5505 Universidade Federal de Alagoas, Brasil E-mail: almericee@gmail.com

Sueli Terezinha Cruz Rodrigues ORCID: https://orcid.org/0000-0002-2697-4714 Universidade Federal de Alagoas, Brasil E-mail: suelitcr@gmail.com

Amuzza Aylla Pereira dos Santos ORCID: https://orcid.org/0000-0001-6299-7190 Universidade Federal de Alagoas, Brasil E-mail: amuzza.pereira@eenf.ufal.br

Maria Elisângela Torres de Lima Sanches ORCID: https://orcid.org/0000-0001-8987-3825 Universidade Federal de Alagoas, Brasil E-mail: eli_sanches23@hotmail.com

Siane Mariano Alves ORCID: https://orcid.org/0000-0002-0385-1746 Universidade Federal de Alagoas, Brasil E- mail: siane_mariano@hotmail.com

Larissa Thaís Omena dos Santos ORCID: https://orcid.org0000-0001-5500-0436 Universidade Federal de Alagoas, Brasil E-mail:larissa_thais_s@hotmail.com

Tayse Lopes Alves ORCID: https://orcid.org/0000-0001-8864-0413 Universidade Federal de Alagoas, Brasil E-mail: tayselalves@gmail.com

\begin{abstract}
Resumo
Objetivo: Sintetizar o conhecimento produzido na literatura científica nos últimos cinco anos, acerca do impacto do diagnóstico do HumanImmunodeficiency Vírus (HIV) na gestação ou pós-parto e seus efeitos na vida das mulheres. Metodologia: Trata-se de um artigo do tipo revisão integrativa de literatura de natureza qualitativa, com estudos primários publicados no recorte temporal de 2015 a 2020, nos idiomas português e inglês, nas bases de dados MedLine, Lilacs e BDEnf através da Biblioteca Virtual da Saúde (BVS), e PubMed, com o uso de estratégias de buscas, de acordo com as especificidades das bases de dados em questão. Resultados: Foram selecionados 11 estudos primários, dos quais foram extraídas as seguintes categorias: 1) Sentimentos das mulheres ao receber o diagnóstico de HIV na gestação ou pós-parto; 2) Implicações da revelação do diagnóstico ao parceiro, familiares e outros. 3) A maternidade e o HIV, os principais desafios enfrentados pelas mães após o diagnóstico. 4) O papel dos profissionais de saúde na assistência às gestantes e puérperas diagnosticadas com o HIV. Conclusão: Esta revisão de literatura reforça a necessidade de mais trabalhos que abordam as implicações da descoberta do HIV na gestação ou pós-parto e que possibilitem a compreensão dos profissionais de saúde acerca de tais implicações para que se possa traçar estratégias para minimizá-las. Espera-se que este estudo possa despertar o interesse pelo tema abordado, para que sejam desenvolvidos trabalhos e também ações que possam contribuir para a promoção da saúde das mulheres diagnosticadas com o HIV nas Unidades Básicas de Saúde (UBSs) ou maternidades através de intervenções baseadas nas demandas encontradas com o uso de estratégias que atendam às necessidades individuais de cada mulher, que promovam qualidade de vida e possibilitem a ressignificação da vida após o diagnóstico do HIV.
\end{abstract}

Palavras-chave: Gestação; Parto; Maternidade; Diagnóstico; HIV; Enfermagem. 


\begin{abstract}
Objective: To synthesize the knowledgeproduced in the scientificliterature in the lastfiveyears, about the impact of the diagnosis of the HumanImmunodeficiencyVirus (HIV) in pregnancy or postpartum and its effects on the lives of women.Methodology: This is an integrativeliterature review of a qualitativenature, with primarystudiespublished in the time frame from 2015 to 2020, in Portuguese and English, in the MedLine, Lilacs and BDEnfdatabasesthrough the Virtual Health Library (VHL), and PubMed, usingsearch strategies, according to the specificities of the databases in question. Results: 11 primarystudieswereselected, from which the following categorieswereextracted: 1) Feelings of women when receiving the diagnosis of HIV during pregnancy or postpartum; 2) Implications of disclosing the diagnosis to the partner, familymembers and others. 3) Motherhood and HIV, the mainchallengesfaced by mothers after diagnosis. 4) The role of health professionals in assisting pregnant women and women who have recentlybeen diagnosed with HIV. Conclusion: This literature review reinforces the need for more studies that address the implications of HIV discovery during pregnancy or postpartum and that enable health professionals to understandaboutthese implications so that strategies can be devised to minimize them. It is hoped that this study may arouseinterest in the topicaddressed, so that work and also actions that can contribute to the promotion of the health of women diagnosed with HIV in Basic Health Units (UBSs) or maternityunitsthrough interventions based on interventions are developed. in the demandsfound with the use of strategies that meet the individual needs of eachwoman, that promote quality of life and enable the re-signification of life after HIV diagnosis.
\end{abstract}

Keywords: Gestation; Childbirth; Maternity; Diagnosis; VIH; Nursing.

\begin{abstract}
Resumen
Objetivo: Sintetizar losconocimientosproducidosenla literatura científica enlos últimos cinco años, sobre el impacto del diagnóstico delVirus de laInmunodeficiencia Humana (VIH) enelembarazo o posparto y sus efectosenla vida de lasmujeres. Metodología: Se trata de una revisión integradora de la literatura de carácter cualitativo, conestudiosprimarios publicados enel marco temporal de 2015 a 2020, enportugués e inglés, enlas bases de datosMedLine, Lilacs y BDEnf a través de la Biblioteca Virtual enSalud (BVS) y PubMed, utilizando estrategias de búsqueda. segúnlas especificidades de las bases de datosencuestión. Resultados: Se seleccionaron 11 estudiosprimarios, de loscuales se extrajeronlassiguientescategorías: 1) Sentimientos de lamujer al recibirel diagnóstico de VIH durante elembarazo o posparto; 2) Implicaciones de revelar el diagnóstico a lapareja, familiares y otros. 3) Maternidad y VIH, losprincipales retos a los que se enfrentanlas madres trasel diagnóstico. 4) El papel de losprofesionales de lasaludenlaasistencia a lasmujeresembarazadas y a las que han sido diagnosticadas recientementeconel VIH. Conclusión: Esta revisión de la literatura refuerzalanecesidad de más estudios que abordenlasimplicacionesdeldescubrimientodel VIH durante elembarazo o elposparto y que permitan a losprofesionales de lasaludcomprender estas implicaciones para que se puedandiseñarestrategias para minimizarlas.Se espera que este estudiopueda despertar interésenel tema abordado, de manera que se desarrollentrabajos y tambiénacciones que puedan contribuir a lapromoción de lasalud de lasmujeres diagnosticadas con VIH en Unidades Básicas de Salud (UBS) o unidades de maternidad a través de intervenciones basadasenel demandas encontradas conel uso de estrategias que satisfaganlasnecesidadesindividuales de cada mujer, que promuevanlacalidad de vida y permitanlaresignificación de la vida despuésdel diagnóstico de VIH.
\end{abstract}

Palabras clave: Gestación; Parto; Maternidad; Diagnóstico; VIH; Enfermería.

\title{
1. Introdução
}

HIV é a sigla em inglês do vírus da imunodeficiência humana, (HumanImmunodeficiency Vírus), sendo este o retrovírus causador da Síndrome da Imunodeficiência adquirida (SIDA; AIDS - AcquiredImmunodeficiencySyndrome). O HIV compromete o sistema imunológico que é responsável por defender o organismo de doenças. Sendo assim, o objeto desse estudo é o impacto do diagnóstico de HIV na gestação e pós-parto.

No Brasil, os primeiros casos de AIDS ocorreram na década de 80 e foram considerados uma epidemia que rapidamente tornou-se um problema de saúde pública. Desde 2006, o HIV na gestação é agravo de notificação compulsória. (Brasil, 2018; Domingues, Saraceni\& Leal, 2018; Lima et al., 2017).O diagnóstico da infecção causada pelo HIV, no Brasil, ganhou um forte aliado, são os testes rápidos, esses foram criados na década de 1980 e popularizados mundialmente a partir da década seguinte. Foram incorporados à rede pública de saúde brasileira a partir de 2005 (Brasil, 2018). O Ministério da saúde recomenda que a testagem rápida para o HIV nas gestantes deve ser realizada na primeira consulta do pré-natal (idealmente, no primeiro trimestre da gestação), no início do terceiro trimestre e no momento do parto (Brasil, 2019). Ainda segundo com Brasil, a testagem deve ser realizada também em qualquer outro momento em que haja exposição de risco ou violência sexual. 
Ainda de acordo com Brasil (2019), o diagnóstico e o tratamento precoce do HIV, contribui de forma positiva para um nascimento saudável do bebê, logo, se observa a importância do pré-natal adequado com realização dos testes rápidos e sorologias recomendadas durante a gestação. Ademais, possibilita um melhor acompanhamento pelos profissionais de saúde, desde o momento do diagnóstico, parto e pós-parto.

Segundo Brasil (2019), o profissional de saúde na avaliação inicial da pessoa recém diagnosticada com HIV deve estabelecer uma boa relação com linguagem adequada e explicar os aspectos essenciais da infecção pelo HIV e a importância do acompanhamento clínico - laboratorial e da terapia antirretroviral (TARV).

\section{Metodologia}

\subsection{Caracterização do estudo}

De acordo com Pereira, Shituka, Parreira e Shitsuka (2018), artigos científicos são documentos que apresentam textos atuais sobre experiências realizadas, relatos de casos ou revisões de literatura. Este estudo trata-se de uma pesquisa de natureza qualitativa, sendo esta uma revisão integrativa de literatura, cujo objetivo visa "reunir e sintetizar resultados de pesquisas sobre um delimitado tema ou questão, de maneira sistemática e ordenada, contribuindo para o aprofundamento do conhecimento do tema investigado" (Mendes, Silveira \& Galvão, 2008). Além disso, se fez uso do modelo elaborado por Tostes e Galvão (2019), onde eles propõem um guia para elaboração de uma revisão integrativa de literatura em 5 etapas, sendo eles as seguintes: Elaboração da questão de pesquisa; Busca na literatura dos estudos primários; Avaliação dos estudos primários; Análise dos dados; Apresentação da revisão, respectivamente.

\subsection{Etapas da revisão integrativa}

\subsubsection{Elaboração da questão da pesquisa}

O presente estudo se concentra no seguinte questionamento norteador: Qual a produção científica dos últimos cinco anos sobre o impacto do diagnóstico do HIV na gestação ou pós-parto e seus efeitos na vida das mulheres.

\subsubsection{Busca na literatura dos estudos primários}

A busca dos estudos foi realizada no período de 18 de maio a 10 de junho de 2020, nas bases de dados: LILACS (Literatura Latino-Americana e do Caribe em Ciências da Saúde), Medline (Literatura Internacional em Ciências da Saúde), BDENF (Banco de dados em Enfermagem), através da BVS (Biblioteca Virtual em Saúde), e PubMed (National Library of Medicine).

As estratégias de busca dos artigos foram adaptadas de acordo com as especificidades de acesso das bases de dados. Para a pesquisa dos artigos nas bases de dados, foram utilizadas as palavras-chave: Diagnóstico, HIV, Gestante, Parto, Maternidade e Sentimentos, e em todas as estratégias de buscas foi utilizado o operador booleano AND.

Os critérios de inclusão adotados para selecionar os estudos primários foram: Tratar-se de estudo primário em formato de artigo; Ter como tema central o Diagnóstico de HIV na gestação ou pós-parto; ter o texto completo disponível para consulta na integra; ter sido publicado nos idiomas português, inglês ou espanhol e ter sido publicado no recorte temporal de 2015 a 2020.

Quanto aos critérios de exclusão, foram excluídas as teses, dissertações, monografias, editoriais, revisões integrativas e conceituais e estudos primários repetidos em mais de uma base pesquisada. Após a aplicação dos critérios de inclusão e exclusão, os estudos tiveram os seus respectivos títulos e resumos lidos e aqueles não relacionados ao objeto de estudo foram 
excluídos. Após este resultado parcial, foi procedida a leitura dos estudos na íntegra e, por fim, excluídos aqueles que não correspondiam ao objeto de estudo. Após esta etapa restaram 11 estudos que foram inseridos nesta pesquisa.

\subsubsection{Avaliação dos estudos primários}

Para avaliação dos estudos primários, foi construído um instrumento para analisar os estudos selecionados, cujo objetivo do referido instrumento é organizar as informações para análise posterior, contendo os seguintes dados: ano de publicação, título, autores, país de publicação, tipo de estudo, objetivo e conclusão.

Os estudos receberam um código de identificação (COD), contendo a letra A seguida de um número, começando pelo número 01. O referido instrumento está disponível para visualização no Apêndice A.

\subsubsection{Análise dos dados}

A análise dos dados foi realizada a partir das informações obtidas após as buscas dos estudos, considerando a pergunta norteadora e o objetivo desta pesquisa.

\subsubsection{Apresentação da revisão integrativa}

A apresentação deste estudo foi organizada com o uso de quadros para melhor compreensão dos resultados obtidos.

\section{Resultados}

Quadro 1 apresenta as estratégias de busca, as bases de dados utilizadas, os resultados obtidos sem os critérios de inclusão e exclusão e os resultados com os critérios de inclusão: Disponível na íntegra, publicados em português, inglês e espanhol e publicado entre 2015 e 2020. Após exclusão dos artigos com os critérios de exclusão, realizou-se a leitura do título e resumo, e por fim foram selecionados aqueles que se adequaram ao critério de inclusão - ter como tema central o Diagnóstico de HIV na gestação ou pós-parto - para compor a amostra final da revisão integrativa de literatura. 
Quadro 1 - Estratégias de busca, bases de dados, e resultado de artigos encontrados.

\begin{tabular}{|c|c|c|c|c|c|c|c|c|c|}
\hline $\begin{array}{l}\text { Estratégia } \\
\text { de busca }\end{array}$ & $\begin{array}{l}\text { Bases de } \\
\text { dados }\end{array}$ & $\begin{array}{c}\text { Resultados } \\
\text { sem aplicação } \\
\text { dos critérios } \\
\text { de inclusão/ } \\
\text { exclusão }\end{array}$ & $\begin{array}{l}\text { Disponível } \\
\text { na íntegra }\end{array}$ & $\begin{array}{l}\text { Publicados } \\
\text { em } \\
\text { português, } \\
\text { inglês ou } \\
\text { espanhol }\end{array}$ & $\begin{array}{c}\text { Publicados } \\
\text { entre } 2015 \\
\text { e } 2020\end{array}$ & $\begin{array}{c}\text { Após } \\
\text { exclusão } \\
\text { dos } \\
\text { repetidos }\end{array}$ & $\begin{array}{l}\text { Estudos } \\
\text { primários }\end{array}$ & $\begin{array}{c}\text { Após } \\
\text { leitura } \\
\text { do } \\
\text { título e } \\
\text { resumo }\end{array}$ & Selecionados \\
\hline \multirow{2}{*}{$\begin{array}{l}\text { Maternidade } \\
\text { AND HIV } \\
\text { AND } \\
\text { Sentimentos }\end{array}$} & $\begin{array}{c}\text { BVS/Lilacs/ } \\
\text { Medline/BDENF }\end{array}$ & 26 & 22 & 22 & 07 & 06 & 05 & 04 & 04 \\
\hline & Pubmed & 22 & 08 & 08 & 07 & 04 & 02 & 02 & 01 \\
\hline \multirow[t]{2}{*}{$\begin{array}{c}\text { Diagnóstico } \\
\text { AND HIV } \\
\text { AND Parto }\end{array}$} & $\begin{array}{c}\text { BVS/Lilacs/ } \\
\text { Medline/BDENF }\end{array}$ & 856 & 461 & 452 & 169 & 166 & 156 & 06 & 03 \\
\hline & PubMed & 204 & 119 & 119 & 66 & 61 & 60 & 00 & 00 \\
\hline \multirow{2}{*}{$\begin{array}{l}\text { Gestante AND } \\
\text { HIV AND } \\
\text { Maternidade }\end{array}$} & $\begin{array}{l}\text { BV/Lilacs/Medline/ } \\
\text { BDENF }\end{array}$ & 32 & 19 & 19 & 04 & 01 & 01 & 01 & 01 \\
\hline & PubMed & 50 & 24 & 24 & 11 & 11 & 11 & 05 & 02 \\
\hline
\end{tabular}

Fonte: Autores (2020).

O Quadro 1 mostra de forma simplificada os resultados obtidos durante as buscas dos estudos para compor a amostra deste trabalho. Nota-se que nas primeiras buscas o número de estudos era bem significativo foi diminuindo à medida que os filtros eram aplicados. A primeira coluna é composta por 3 combinações de palavras separadas pelo operador booleano AND. $\mathrm{Na}$ segunda coluna aparecem as bases de dados utilizadas para as pesquisas, e as demais colunas mostram os filtros utilizados e os resultados distribuídos à medida que os filtros eram aplicados. A última coluna representa o número total de estudos selecionados para compor este trabalho. 
Quadro 2 - Síntese da amostra.

\begin{tabular}{|c|c|c|c|c|c|}
\hline COD & Ano & Títulos/autores & $\begin{array}{l}\text { Tipo de } \\
\text { estudo }\end{array}$ & Objetivo & Conclusão \\
\hline A01 & 2015 & $\begin{array}{l}\text { Maternity perception by } \\
\text { pregnant women living } \\
\text { with HIV } \\
\text { Spindola, T., Dantas, K. T. } \\
\text { B., Cadavez, N. F. V., } \\
\text { Fonte, V. R. F. D., \& } \\
\quad \text { Oliveira, D. C. }\end{array}$ & $\begin{array}{c}\text { Estudo de } \\
\text { desenho } \\
\text { descritivo e } \\
\text { abordagem } \\
\text { qualitativa }\end{array}$ & $\begin{array}{l}\text { Identificar a percepção das } \\
\text { gestantes que vivem com o } \\
\text { HIV sobre a maternidade e } \\
\text { conhecer as expectativas e } \\
\text { os sentimentos vivenciados } \\
\text { por essas mulheres. }\end{array}$ & $\begin{array}{l}\text { Ser mãe e viver com HIV envolve vários sentimentos, conflitos e } \\
\text { dificuldades impostas por sua condição, na qual uma perspectiva positiva } \\
\text { para o futuro é bastante desejável. No entanto, existe a crença de que a } \\
\text { maternidade associada ao HIV é cercada por incertezas, ansiedades e medos. } \\
\text { As gestantes, neste estudo, expressaram que viver com HIV não muda o } \\
\text { conceito do que é ser mãe. Mãe. Pelo contrário, todos consideraram que a } \\
\text { maternidade é uma experiência positiva em suas vidas, deixando claro que o } \\
\text { processo de se tornar mãe é um pouco diferente do de uma mulher } \\
\text { soronegativa. }\end{array}$ \\
\hline A02 & 2015 & $\begin{array}{l}\text { Representações maternas } \\
\text { no contexto do HIV: } \\
\text { gestação ao segundo ano } \\
\text { da criança } \\
\text { Faria, E. R., Piccinini, C. } \\
\quad \text { A. }\end{array}$ & $\begin{array}{l}\text { Análise de } \\
\text { conteúdo } \\
\text { qualitativa }\end{array}$ & $\begin{array}{l}\text { Investigar a relação mãe- } \\
\text { bebê no contexto do HIV, } \\
\text { da gestação ao segundo ano } \\
\text { de vida da criança, a partir } \\
\text { do conceito de } \\
\text { representações maternas de } \\
\quad \text { Stern (1997). }\end{array}$ & $\begin{array}{l}\text { Os achados do presente estudo ressaltam a importância de ampliar, } \\
\text { oferecendo-se, atenção especial à saúde mental materna com o intuito de se } \\
\text { proteger, também, a criança em desenvolvimento. Tal atenção consiste, } \\
\text { também, em compreender os componentes sociais e ainda estigmatizadores } \\
\text { que circundam o HIV, aos quais essas mães estão sujeitas. Acolhê-las, } \\
\text { promover a busca de seus direitos e auxiliá-las a encontrar apoio social e } \\
\text { familiar efetivo são aspectos fundamentais do atendimento a estas mães. }\end{array}$ \\
\hline A03 & 2016 & $\begin{array}{l}\text { We have beaten HIV a } \\
\text { bit': a qualitative study of } \\
\text { experiences of peer } \\
\text { support during pregnancy } \\
\text { with an HIV Mentor } \\
\text { Mother project in England } \\
\text { McLeish J, \& Redshaw, } \\
\text { M. }\end{array}$ & $\begin{array}{l}\text { Qualitative } \\
\text { descriptive } \\
\text { study }\end{array}$ & $\begin{array}{l}\text { To explore the experiences } \\
\text { of women living with HIV } \\
\text { in England who received or } \\
\text { gave Mentor Mother } \\
\text { (trained mother-to-mother) } \\
\text { volunteer peer support } \\
\text { during pregnancy and early } \\
\text { motherhood. }\end{array}$ & $\begin{array}{l}\text { A Mentor Mother peer support programme is acceptable to, and valued by, } \\
\text { black African mothers with HIV, in England. Peer support from trained } \\
\text { volunteers during and after pregnancy can complement and reinforce medical } \\
\text { advice on avoiding mother-to-child transmission of HIV, and can have a } \\
\text { multidimensional positive impact on vulnerable mothers' emotional well- } \\
\text { being, Mentor Mother peer support should be considered by those designing } \\
\text { programmes for the support of pregnant women with HIV and the prevention } \\
\text { of mother-to child transmission of HIV. }\end{array}$ \\
\hline
\end{tabular}


Research, Society and Development, v. 10, n. 3, e17010313157, 2021

(CC BY 4.0) | ISSN 2525-3409 | DOI: http://dx.doi.org/10.33448/rsd-v10i3.13157

\begin{tabular}{|c|c|c|c|c|c|}
\hline COD & Ano & Títulos/autores & Tipo de estudo & Objetivo & Conclusão \\
\hline A04 & 2016 & $\begin{array}{c}\text { I Owe Her So Much; } \\
\text { Without Her I Would Be } \\
\text { Dead \&quot; Developing } \\
\text { a Model of Mother-Infant } \\
\text { Bonding Following a } \\
\text { Maternal Antenatal HIV } \\
\text { Diagnosis. } \\
\text { Willcocks, K., Evangeli, } \\
\text { M., Anderson, J., Zetler, } \\
\text { S., \&Scourse, R }\end{array}$ & $\begin{array}{l}\text { Exploratory } \\
\text { study; A cross- } \\
\text { sectional } \\
\text { qualitative design } \\
\text { was used. }\end{array}$ & $\begin{array}{l}\text { Our exploratory study } \\
\text { aimed to develop a } \\
\text { theoretical model of } \\
\text { mother-infant bonding } \\
\text { following na antenatal } \\
\text { HIV diagnosis }\end{array}$ & $\begin{array}{l}\text { Our study findings may, therefore, be relevant for practitioners supporting } \\
\text { women antenatally diagnosed with HIV both within the United Kingdom } \\
\text { and globally. }\end{array}$ \\
\hline $\mathrm{A} 05$ & 2016 & $\begin{array}{l}\text { Testing HIV positive in } \\
\text { pregnancy: A } \\
\text { phenomenological study } \\
\text { of women's experiences } \\
\text { Lingen-Stallard, A., } \\
\text { Furber, C., \& Lavender, T. }\end{array}$ & $\begin{array}{l}\text { Qualitative, } \\
\text { phenomenologica } \\
\text { l approach. }\end{array}$ & $\begin{array}{l}\text { This study aims to explore } \\
\text { women's experiences of } \\
\text { receiving a positive HIV } \\
\text { test results following } \\
\text { antenatal screening. }\end{array}$ & $\begin{array}{l}\text { This study gives midwives unique understanding of the complexities and } \\
\text { major implications for women who tested positive for HIV.Women's } \\
\text { Experiences resonated with processes of bereavement, providing useful } \\
\text { insight into a transitional and transformational period, during which } \\
\text { appropriate support can be targeted Implications: midwives are crucial } \\
\text { improving the experience of women when they test HIV positive. }\end{array}$ \\
\hline A06 & 2017 & $\begin{array}{l}\text { Mães adolescentes que } \\
\text { vivem com o HIV: uma } \\
\text { investigação qualitativa } \\
\text { sobre a "Constelação da } \\
\text { Maternidade" } \\
\text { Pinto, M. D., Maia, G. N., } \\
\text { Pereira, M D., } \\
\text { \&Levandowski, D. C. }\end{array}$ & $\begin{array}{l}\text { Análise de } \\
\text { conteúdo } \\
\text { qualitativa }\end{array}$ & $\begin{array}{l}\text { Examinar, entre mães } \\
\text { adolescentes que vivem } \\
\text { com o HIV, os temas } \\
\text { centrais referentes à CM } \\
\text { proposta por Stern (1997) }\end{array}$ & $\begin{array}{c}\text { Estudos futuros necessitam ser realizados com amostras de maior } \\
\text { dimensão e empregando um delineamento longitudinal para uma avaliação } \\
\text { mais compreensiva da Constelação da Maternidade, a fim de identificar } \\
\text { eventuais mudanças nos aspectos investigados, tais como rede de apoio e } \\
\text { organização identitária. }\end{array}$ \\
\hline
\end{tabular}


Research, Society and Development, v. 10, n. 3, e17010313157, 2021

\begin{tabular}{|c|c|c|c|c|c|}
\hline COD & Ano & Títulos/autores & Tipo de estudo & Objetivo & Conclusão \\
\hline A07 & 2018 & $\begin{array}{c}\text { A invenção da vida na } \\
\text { gestação: viver com } \\
\text { HIV/aids e a } \\
\text { produção do cuidado. } \\
\text { Medeiros, D. S., \& } \\
\text { Jorge, M. S. B. }\end{array}$ & $\begin{array}{l}\text { Pesquisa } \\
\text { qualitativa de } \\
\text { orientação } \\
\text { cartográfica }\end{array}$ & $\begin{array}{l}\text { Acompanhar os processos } \\
\text { de produção do cuidado no } \\
\text { entrelaçamento das redes } \\
\text { formais de atenção à saúde } \\
\text { e as redes informais. }\end{array}$ & $\begin{array}{l}\text { Uma gestação com HIV requer ferramentas de cuidado que extrapolem o } \\
\text { diagnóstico e o tratamento. Não basta saber a condição sorológica e ofertar o } \\
\text { medicamento, é necessário compreender como se organiza o território } \\
\text { existencial da mulher para uma resposta efetiva à infecção pelo HIV. }\end{array}$ \\
\hline A08 & 2019 & $\begin{array}{l}\text { "It Was as Though } \\
\text { My Spirit Left, Like } \\
\text { They Killed Me": The } \\
\text { Disruptive Impact of } \\
\text { an HIV-Positive } \\
\text { Diagnosis among } \\
\text { Women in the } \\
\text { Dominican Republic } \\
\text { Payán, D. D., Derose } \\
\text { K.P., Fulcar M. A., } \\
\text { Farías, H., \&Palar, K. }\end{array}$ & $\begin{array}{l}\text { Qualitative } \\
\text { approach }\end{array}$ & $\begin{array}{l}\text { Explore the impact of an } \\
\text { HIV diagnosis on WLHIV } \\
\text { in the DR and coping } \\
\text { strategies after } \\
\text { diagnosis. }\end{array}$ & $\begin{array}{l}\text { WLHIV in the DR may benefit from counseling and support services to } \\
\text { improve their treatment adherence and quality of life. Culturally appropriate } \\
\text { behavioral and social support interventions, such health services and HIV peer } \\
\text { support groups, are needed in low-resource settings to mitigate the negative } \\
\text { impacts of an HIV-positive diagnosis that impede RT adherence, appropriate } \\
\text { self-management, and quality of life among PLHIV. Continued efforts to } \\
\text { reduce HIV-related stigma more broadly are also needed for improved } \\
\text { outcomes across the HIV care continuum. }\end{array}$ \\
\hline A09 & 2019 & $\begin{array}{c}\text { Análise qualitativa } \\
\text { dos sentimentos e } \\
\text { conhecimentos acerca } \\
\text { da gestação e do HIV } \\
\text { em gestantes } \\
\text { soropositivas e } \\
\text { soronegativas } \\
\text { Hernandes, C. P., } \\
\text { Rocha, R. K., } \\
\text { Hausmann, A., } \\
\text { Appelt, J. B., \& } \\
\text { Marques, C. M. }\end{array}$ & $\begin{array}{c}\text { Estudo } \\
\text { transversal } \\
\text { qualitativo de } \\
\text { casos coletivos }\end{array}$ & $\begin{array}{l}\text { Análise epidemiológica, da } \\
\text { percepção e expectativa das } \\
\text { gestantes portadoras do } \\
\text { HIV em relação ao filho, de } \\
\text { questões relacionadas ao } \\
\text { autocuidado antes e durante } \\
\text { a gestação, comparando } \\
\text { com gestantes que } \\
\text { apresentam gestação de alto } \\
\text { risco, mas soronegativas. }\end{array}$ & $\begin{array}{l}\text { É essencial a existência de uma equipe multidisciplinar preparada para lidar } \\
\text { com os conflitos das gestantes, além de educá-las quanto às formas de } \\
\text { transmissão vertical. Em especial no grupo soropositivo, o apoio psicológico } \\
\text { quanto ao medo de transmissão vertical e ao processo de confrontar o fato de } \\
\text { não poder amamentar faz necessário, pois isso estabelece uma confiança } \\
\text { mútua, tanto da paciente em relação a equipe de saúde, quanto da equipe em } \\
\text { relação à paciente, algo que é central para a saúde da mãe e do bebê. }\end{array}$ \\
\hline
\end{tabular}




\begin{tabular}{|c|c|c|c|c|c|}
\hline COD & Ano & Títulos/autores & Tipo de estudo & Objetivo & Conclusão \\
\hline A10 & 2019 & $\begin{array}{l}\text { Sentimentos e } \\
\text { significados: HIV na } \\
\text { impossibilidade de } \\
\text { amamentar/ Feelings } \\
\text { and meanings: HIV in } \\
\text { the impossibility of } \\
\text { breastfeeding } \\
\text { Souza, F. L. P., Clark, } \\
\text { L. M., Lelis, B. D. B., } \\
\text { Dusso, M. I. S., \& } \\
\text { Leite, A. M. }\end{array}$ & $\begin{array}{l}\text { Estudo } \\
\text { qualitativo, } \\
\text { descritivo, } \\
\text { exploratório, } \\
\text { fenomenológico. }\end{array}$ & $\begin{array}{l}\text { Interpretar os sentimentos e } \\
\text { significados que as } \\
\text { mulheres que vivem com } \\
\text { HIV/Aids atribuem à } \\
\text { impossibilidade de } \\
\text { aleitamento e à } \\
\text { maternidade. }\end{array}$ & $\begin{array}{l}\text { Denotou-se, sentimentos de angústia, medo, autodesprezo, negação da própria } \\
\text { condição de saúde, isolamento e solidão devido ao receio do preconceito } \\
\text { social. Nota-se que, além disso, atribuem o vírus do HIV diretamente à Aids, } \\
\text { com suas extremas complicações, relacionam a possibilidade de vir a óbito e } \\
\text { deixar seus filhos sozinhos. Revela-se em contraponto que, após o } \\
\text { conhecimento das condições de tratamento, sentem-se mais seguras e } \\
\text { esperançosas. Relatou-se que sobre o apoio emocional nas horas difíceis, } \\
\text { buscam na fé e na perspectiva de viver para cuidar dos filhos e vê-los crescer } \\
\text { saudáveis. }\end{array}$ \\
\hline A11 & 2019 & $\begin{array}{c}\text { Síndrome da } \\
\text { imunodeficiência } \\
\text { humana na criança: } \\
\text { repercussões para a } \\
\text { família } \\
\text { Pacheco, B. P., Nobre, } \\
\text { C. M. G., Costa, A. R., } \\
\text { Nornberg, P. K. O., } \\
\text { Medeiros, S. P., } \\
\text { Gomes, G. C. }\end{array}$ & $\begin{array}{c}\text { Estudo } \\
\text { qualitativo e } \\
\text { descritivo }\end{array}$ & $\begin{array}{l}\text { Conhecer as repercussões } \\
\text { do diagnóstico de crianças } \\
\text { com o vírus da } \\
\text { imunodeficiência humana } \\
\text { para a família. }\end{array}$ & $\begin{array}{l}\text { Fornecem-se informações, diante das principais dificuldades referidas pelas } \\
\text { mães ao receberem o diagnóstico, para que a equipe de saúde promova ações a } \\
\text { serem implementadas o mais precocemente possível como forma de } \\
\text { instrumentalização da família para o cuidado e de incentivo ao viver saudável } \\
\text { da criança. }\end{array}$ \\
\hline
\end{tabular}

Fonte: Autores (2020). 
O Quadro 2 mostra de forma detalhada a síntese da amostra desta pesquisa. Neste quadro aparece um código de identificação do estudo, o ano de publicação, título e autores, tipo de estudo, objetivo e por fim a conclusão do estudo.

Os estudos primários que compõem este estudo foram agrupados em categorias, para fins de entendimento dos leitores, conforme (Quadro 3).

Quadro 3 - Distribuição dos estudos por categorias.

\begin{tabular}{|c|c|}
\hline Categoria & Estudos \\
\hline $\begin{array}{c}\text { Sentimentos das mulheres ao receber o diagnóstico de HIV na gestação } \\
\text { ou pós-parto. }\end{array}$ & $\begin{array}{c}\text { A01; A02; A03; A04; A05; A06; } \\
\text { A07; A08; A09; A10; A11. }\end{array}$ \\
\hline $\begin{array}{c}\text { Implicações da revelação do diagnóstico ao parceiro, familiares e outros. } \\
\text { a maternidade e o HIV, os principais desafios enfrentados pelas mães } \\
\text { A } 0 \text { A } 03 \text { A } 03 \text { A05; A08; A09; A10. }\end{array}$ & $\begin{array}{c}\text { A01; A02 A03; A04; A06; A08; } \\
\text { A09; A10; A11. }\end{array}$ \\
\hline $\begin{array}{c}\text { O papel dos profissionais de saúde na assistência às gestantes e } \\
\text { puérperas diagnosticadas com o HIV }\end{array}$ & $\begin{array}{c}\text { A01; A02 A03; A04; A05; A06; } \\
\text { A07; A08; A09; A10; A11. }\end{array}$ \\
\hline
\end{tabular}

Fonte: Autores (2020).

O Quadro 3 mostra a distribuição dos estudos selecionados por categorias. Na coluna da esquerda aparecem as 4 categorias e na coluna da direita os códigos dos estudos agrupados de acordo com as categorias às quais estes se enquadram. Ressalta-se que alguns artigos abordam temas que se enquadram em mais de uma categoria.

\section{Discussão}

Ao analisar os estudos primários que compõem esta revisão integrativa, no que se refere ao ano de publicação, observa-se o seguinte cenário: No ano de 2019 foram publicados (4 estudos), seguido de 2016 com (3 estudos), 2015 com ( 2 estudos), 2017 e 2018 com (1 estudo) cada. Quanto aos países em que foram desenvolvidos e publicados, em ordem decrescente de número de estudos, temos o seguinte cenário: Brasil (7 estudos), Inglaterra (3 estudos), República Dominicana (1 estudo).

Quanto ao número de estudos selecionados por base de dados, dentre as escolhidas através da BVS, o maior número de estudos selecionados para a fase final foi obtido na LILACS de onde foram selecionados 4 estudos, seguida por Medline e BDENF com 2 estudos cada. Com o objetivo de ampliar a investigação em bases internacionais, foram realizadas buscas na base de dados PubMed, na qual os descritores foram colocados em língua inglesa, seguindo os critérios da referida base de dados, sendo selecionados para a etapa final 3 estudos, somando assim um total de 11 estudos conforme foi mostrado nos resultados.

Embora tenham sido selecionados os idiomas português, inglês e espanhol nos filtros de buscas das bases de dados, nenhum artigo em língua espanhola foi selecionado na etapa final, restando ( 7 estudos) publicados em língua portuguesa e (4 estudos) em língua inglesa.

Para uma melhor compreensão dos principais achados que envolvem o tema em questão, foram criadas 4 categorias. A saber: 1) Sentimentos das mulheres ao receber o diagnóstico de HIV na gestação ou pós-parto; 2) Implicações da revelação 
do diagnóstico ao parceiro, familiares e outros. 3) A maternidade e o HIV, os principais desafios enfrentados pelas mães após o diagnóstico. 4) O papel dos profissionais de saúde na assistência às gestantes e puérperas diagnosticadas com o HIV.

\subsection{Sentimentos das mulheres ao receber o diagnóstico de HIV na gestação ou pós-parto}

A gestação é um processo fisiológico caracterizado por mudanças físicas e emocionais além de expectativas relacionadas à maternidade. Um diagnóstico de HIV positivo na gestação ou pós-parto pode desencadear pensamentos desorganizados, acompanhados de dúvidas, frente ao que pode parecer uma ameaça à própria vida e/ou a do bebê. Segundo Silva et al.(2018), em um estudo realizado no Hospital das Clínicas da Universidade Federal de Minas Gerais foi observado que $60 \%$ das gestantes descobriram o diagnóstico de HIV durante a triagem sorológica do pré-natal ou no momento do parto e, segundo as análises destes resultados, ao saberem do diagnóstico da sorologia positiva do teste anti-HIV, essas gestantes sentiram um impacto negativo nas suas vidas, visto que em geral, elas não se percebiam vulneráveis ao HIV, o que provocou, inicialmente sentimento de indignação, remorso, tristeza e até indiferença.

Para Renesto, Falbo, Souza e Vasconcelos (2014), a descoberta da soropositividade impõe à mulher uma transformação da consciência sobre si mesma e sobre sua vida. Além disso, os autores descrevem a percepção dessas mulheres de um certo distanciamento na relação com os profissionais de saúde.

Payán, Derose, Fulcar, Farías e Palar (2019), em seu estudo observaram que a maioria das entrevistadas descreveu os impactos imediatos de um diagnóstico positivo para o HIV como sendo psicológico e emocional e ser diagnosticada durante a gestação ou no pós-parto foi descrito como altamente traumático. Lobo et al. (2018) em um estudo realizado em Maceió - AL constataram nos discursos de mulheres vivendo com HIV que o diagnóstico foi recebido por elas com sentimentos de angústia, medo, tristeza, terror, surpresa, incredulidade, injustiça e vergonha. Para Bastos, Bellini, Vieira, Campos e Turato (2019)a confirmação da infecção por HIV na gestação confunde os sentimentos, "tirando o chão" das gestantes, que perdem os referenciais que estruturavam o mundo particular da nova mãe.

Todos os estudos primários selecionados para compor este trabalho abordam os sentimentos relatados pelas mulheres após a descoberta da soropositividade. Apenas um dos estudos, sendo este a cartografia de uma jovem vivendo com HIV em suas 3 gestações, mostra-se diferente dos demais, no que se refere aos sentimentos pós diagnóstico. Medeiros e Jorge (2018) afirmam que a jovem não se abalou com a descoberta do HIV. Entretanto, os autores mostram relatos onde ela expressa sentimentos de medo e preocupação com a exposição e de ser julgada como mãe negligente. Além disso, eles descrevem um momento de choro da jovem no final da entrevista, o que para a autora deste trabalho demonstra um sentimento de tristeza frente a soropositividade e que pode indicar que o fato de ela relatar não ter se abalado com o resultado de HIV positivo poderia estar relacionado a uma fase de negação.

Ainda no que se refere aos sentimentos relatados pelas gestantes e puérperas após o diagnóstico do HIV, a maioria dos autores dos estudos dessa revisão destacam medo, pânico, desespero e choque nas falas das mulheres. Dos onze estudos, sete trazem esses dados, sendo estes: (Spindola, Dantas, Cadavez, Fonte \& Oliveira, 2015; McLeish \& Redshaw, 2016; Pinto, Maia, Pereira \&Levandowski, 2017; Payán, Derose, Fulcar, Farías\& Pala, 2019;Hernandes, Rocha, Hausmann, Appelt\& Marques, 2019; Souza, Clark, Lelis, Dusso\& Leite, 2019; Pacheco et al., 2019).

Segundo Willcocks, Evangeli, Anderson e Scourse (2016), ao receber o diagnóstico do HIV, os pensamentos maternos foram dominados pela ansiedade sobre morte fetal. Esses medos podem permanecer ainda após o nascimento da criança.

No estudo de Pinto et al. (2017) foram evidenciados medos, tais como de que o bebê morresse, parasse de respirar, não comesse, caísse e se machucasse ou de que não viesse a se desenvolver adequadamente. Relatos parecidos que envolvem ansiedade e medo de perder o bebê também são encontrados no estudo de Hernandes et al. (2019). 
De acordo com Bastos et al. (2019), o nascimento costuma ser idealizado e relacionado a sentimentos positivos, mas quando há a possibilidade de contaminação do bebê pelo vírus, a angústia é sentida pela própria mãe. Dentre os estudos selecionados para compor esta revisão de literatura, os que abordam sentimentos de angústia e/ou tristeza são: (Lingen-Stallard, Furber \& Lavender, 2016; Pinto et al. 2017; Payán, Derose, Fulcar, Farías\&Palar, 2019; Hernandes et al., 2019; Souza et al., 2019).

Faria e Piccinini (2015) constataram que no período inicial, envolvendo gestação e primeiros três meses do puerpério, prevaleceram representações de uma mãe bastante culpada pela possível infecção do bebê. Os demais estudos que trazem relatos de culpa e/ou remorso são: (Willcocks et al.,2016; Payán et al., 2019; Hernandes et al., 2019; Pacheco et al., 2019), sendo que este último estudo citado refere-se ao sentimento de culpa da mãe pelo recebimento do diagnóstico da criança, por esta não ter realizado o tratamento durante a gestação.

Lewandowski et al. (2017), apontam em seu estudo que ainda não se conhecem os sentimentos maternos em caso de diagnóstico definitivo negativo do estado sorológico do bebê. Entretanto, pode-se pensar que, mesmo nessa situação, temores de reversão do quadro continuem a fazer parte das vivências das mães.

Outro sentimento encontrado nos estudos analisados que está fortemente ligado à maternidade foi a frustração por não poder amamentar. Os estudos que abordam esse sentimento são: (Faria \& Piccinini, 2015; Pinto et al., 2017; Hernandes et al., 2019; Souza et al.,2019). É importante ressaltar que Pinto, Maia, Pereira e Levandowski (2017) apontam também um sentimento de indiferença frente à impossibilidade de amamentar que se justifica pela sensação de proteger a criança da transmissão vertical. De acordo com Brasil (2019), a decisão de comunicar à puérpera sobre a necessidade de suprimir a lactação apenas após o parto é considerada tardia, com resultados insatisfatórios. Logo, é importante que os profissionais de saúde conversem o quanto antes com as mulheres diagnosticadas com o HIV para que essas possam compreender a importância da não amamentação.

Em alguns dos estudos selecionados para este trabalho aparecem sentimentos de esperança, superação, motivação e gratidão. Segundo Willcocks et al. (2016), algumas mães relataram sentimentos de gratidão e vida mútua entre elas e seus bebês por elas terem descoberto o diagnóstico no pré-natal e realizado tratamento precoce. Ainda segundo os mesmos autores, as mães descreveram seus bebês como trazendo felicidade e significado de volta às suas vidas após a experiência traumática de serem diagnosticados com HIV. Outros estudos em que aparecem sentimentos positivos são: (Spindola et al., 2015; Payán et al., 2019; Hernandes et al., 2019; Souza et al., 2019).

Segundo Souza et al. (2019), apesar do perfil de mudança de pessoas vivendo com HIV/Aids, a má adaptação psicológica ao diagnóstico está fortemente referenciada ao preconceito, estigma e discriminação, que faz com que estas pessoas sintam angústia, medo, vergonha, ansiedade e depressão.

Outras referências que compõem esta revisão também trazem questões relacionadas ao estigma e preconceito. São elas: Lingen-Stallard et al., 2016; Pinto et al., 2017; Medeiros et al., 2018; Payán et al., 2019; Hernandes et al., 2019; Pacheco et al., 2019). De um modo geral, todos os estudos desta revisão de alguma forma abordam o estigma, sendo que Willcocks et al. (2016) trazem nos relatos das mães a percepção de discriminação de seus bebês por familiares, amigos e profissionais por conta do diagnóstico materno do HIV.

De acordo com Andrade e Iriart (2015), o desconhecimento em relação às formas de transmissão do HIV potencializaram o estigma por associação que não se restringiu ao cônjuge, mas a diferentes pessoas que tinham contato com pacientes HIV positivo. Deste modo, as pessoas com HIV temem sofrer preconceito e discriminação. Isso pode explicar a questão do isolamento que aparece nos relatos das mulheres em alguns estudos. Sendo estes: (McLeish \& Redshaw, 2016; Lingen-Stallard et al., 2016; Payán et al., 2019). Segundo Lingen-Stallard et al. (2016), o isolamento foi principalmente auto- 
imposto porque as mulheres não queriam que percebessem que elas haviam mudado após o diagnóstico. Este estudo também traz relatos de mulheres que ficaram irritadas com a descoberta do diagnóstico.

Os resultados do estudo de Bastos et al. (2019), mostram que, o diagnóstico obriga a mulher a usar mecanismos de defesa, como negação, isolamento e desvalorização de si mesma. Neste contexto, a negação aparece nos seguintes estudos: (Lingen-Stallard et al. 2016; Payán et al., 2019; Hernandes et al., 2019). Outros estudos abordam a vergonha, sendo estes: (Willcocks et al., 2016; Souza et al., 2019).

Relatos referentes ao medo do estigma são encontrados nos seguintes estudos: (Spindola et al., 2015; Faria \& Piccinini, 2015; McLeish \& Redshaw., 2016).

Faria e Piccinini (2015) trazem em seu estudo representações de uma mãe temerosa de ser julgada e sofrer preconceito por ser portadora de uma doença estigmatizada e por estar gestando neste contexto. Percebe-se nos estudos analisados que o medo de sofrer preconceito é uma das principais razões pela qual muitas mulheres optam por não divulgar sua condição sorológica, embora esta seja uma difícil decisão a ser tomada. Diante desta constatação, fez-se necessária a criação de uma categoria que será discutida a seguir para melhor abordar a questão da revelação do diagnóstico.

\subsection{Implicações da revelação do diagnóstico ao parceiro, familiares e outros}

Segundo Fernandes et al. (2017), a revelação do diagnóstico para a família e/ou cônjuge e para a sociedade, além de representar um desafio pessoal de aceitação e de enfrentamento, representa um desafio social de quebra de preconceitos e de inclusão. Logo, acredita-se que esta revelação constitui uma das maiores dificuldades enfrentadas pelas pessoas com HIV.

De acordo com Brasil (2020), os grupos mais vulneráveis ao preconceito e discriminação no Brasil podem contar com uma legislação específica. Deste modo, as pessoas vivendo com HIV tem seus direitos garantidos, e alguns desses são encontrados na Declaração dos Direitos Fundamentais da Pessoa Portadora do Vírus da Aids. Este documento aborda entre outras questões referentes à privacidade das pessoas com HIV e seu direito de ter o diagnóstico revelado somente para quem estas consentirem. O parágrafo XIII traz que "Ninguém poderá fazer referência à doença de alguém, passada ou futura, ou ao resultado de seus testes para o HIV/aids, sem o consentimento da pessoa envolvida". O mesmo parágrafo destaca ainda que "A privacidade do portador do vírus deverá ser assegurada por todos os serviços médicos e assistenciais". Já o parágrafo X determina que "Todo portador do vírus tem direito a comunicar apenas às pessoas que desejam seu estado de saúde e o resultado dos seus testes".

Dos estudos primários selecionados para este trabalho, os que trazem questões relacionadas à divulgação do diagnóstico de HIV são: (Spindola et al., 2015; McLeish \& Redshaw, 2016; Lingen-Stallard et al., 2016; Payán et al., 2019; Hernandes et al., 2019; Souza et al., 2019).

Segundo Oliveira et al. (2015), a revelação do diagnóstico ao parceiro possibilita expressar os anseios e inseguranças, além de solicitar ou receber apoio afetivo e cuidados, favorecendo a descoberta de novas experiências sexuais. Neste contexto, Lingen-Stallard et al. (2016), concluem em seu estudo que informar ao parceiro o diagnóstico do HIV é importante para a transição e transformação das mulheres, mas essa divulgação tem implicações como: fim do relacionamento, questões que envolvem a confiança, abuso e perda de controle da divulgação. Este mesmo estudo também traz alguns relatos em que houve agressão após a revelação do diagnóstico.

Ainda segundo Lingen-Stallard et al. (2016), quase todas as participantes do estudo, com exceção de duas, relataram a difusão de estigma dos parceiros, familiares e inclusive de alguns profissionais de saúde e as experiências de estigma dessas mulheres aumentaram as preocupações com a confidencialidade, pois embora elas tenham dado exemplos de como a confidencialidade era mantida, houve casos em que ocorreu a quebra do sigilo por profissionais de saúde. 
Segundo Brasil (2017), o profissional de saúde deve manter sigilo sobre as informações prestadas pelas pessoas vivendo com HIV/aids, (PVHIV), e também garantir a privacidade nos espaços de atendimento no seu serviço. As informações sobre a pessoa com HIV só devem ser compartilhadas com familiares, parceiros ou outras pessoas se houver autorização da mesma. Ressalta-se ainda, que o sigilo é um direito da pessoa, independentemente de qualquer agravo.

Andrade e Iriart (2015), trazem dados de mulheres que relataram ter ocultado o diagnóstico o quanto puderam inclusive para os familiares mais próximos, retraindo-se das relações sociais, como forma de se proteger de uma possível discriminação. Segundo Hernandes et al. (2019), muitas mães sofrem sozinhas e não falam da condição sorológica nem para as pessoas mais próximas em seu ciclo social e elas mostram-se com medo de perder os amigos, os familiares e os filhos.

Souza et al. (2019) apontam em seu estudo relatos de mulheres os quais trazem a discriminação e o afastamento vivenciado por elas após a divulgação do diagnóstico do HIV, sendo este o motivo pelo qual elas preferem manter o sigilo da sua condição sorológica.

De acordo Andrade e Iriart (2015), embora a revelação do diagnóstico seja uma decisão difícil, algumas mulheres decidem falar sobre o diagnóstico no momento em que vão iniciar o tratamento antirretroviral, geralmente por conta da exigência nos serviços de saúde da presença de um parente que acompanhe a paciente.

SegundoSilva, Santos, Cortez e Cordeiro (2015), o apoio familiar tem papel fundamental na adesão ao tratamento do HIV, sendo também um suporte na criação dos filhos devido à necessidade de ter alguém confiável para ajudar nos cuidados com os bebês, ou contribuindo para que as mães tenham mais tempo para dedicar-se a eles.

\subsection{A maternidade e o HIV, os principais desafios enfrentados pelas mães após o diagnóstico}

Ao serem surpreendidas com o diagnóstico do HIV na gestação ou pós-parto as mulheres passam por um processo que pode ir da negação à aceitação, e precisam repensar e reorganizar suas vidas frente aos obstáculos relacionados à soropositividade. De acordo com Spindola et al. (2015), estudos demonstram que, apesar de gestantes diagnosticadas com HIV relatarem que vivenciam uma gestação como a de outras mulheres, situações peculiares são evidenciadas no seu cotidiano. Lewandowski (2017), destaca que o sentimento de angústia parece ser mais intenso entre as mulheres diagnosticadas na gestação ou parto, causados pela necessidade da dupla reorganização de ver-se portadora do HIV e adotar comportamento diferenciado em relação ao cuidado com a criança.

Segundo Hernandes et al. (2019), as mães soropositivas para HIV diagnosticadas previamente veem a gestação como um motivo de superação e materialização de um tratamento feito corretamente, já as mães recém-diagnosticadas no pré-natal podem se sentir culpadas, abaladas e sem estrutura emocional para levar a gestação adiante.

Quando diagnosticadas no pré-natal, as gestantes iniciam uma batalha para evitar a Transmissão Vertical (TV), que inclui o início do tratamento com antirretrovirais e as informações sobre a via de parto recomendada e a não amamentação. Segundo Brasil (2018), Transmissão Vertical é a transmissão dos vírus do HIV/aids, da sífilis e/ou hepatites virais ao bebê durante a gestação, parto ou amamentação.

Ao longo dos anos o incentivo ao parto vaginal e à amamentação foram fortemente introduzidos nas informações prestadas por profissionais de saúde e são compreendidos pelas mulheres como algo importante para elas e para seus bebês. De acordo com Brasil (2019), a partir da $38^{\mathrm{a}}$ semana de gestação a cesárea diminui o risco da TV do HIV no caso das gestantes com Carga Viral (CV) desconhecida ou maior que 1.000 cópias/mL após 34 semanas de gestação. Deste modo, entende-se que já no momento do diagnóstico do HIV as mulheres enfrentam um processo de desconstrução de alguns sonhos e ideais relacionados à maternidade e precisam seguir os protocolos recomendados para prevenir a TV.

Willcocks et al. (2016) apresentam em seu estudo pontos importantes das experiências de gestantes após serem diagnosticadas com HIV. Para muitas delas, o diagnóstico positivo comprometeu o foco em tornar-se mãe, além disso, a 
responsabilidade materna de proteger o bebê foi caracterizada não apenas em termos de proteção contra o HIV, mas também em proteger emocionalmente a criança contra o estigma.

Os autores apontam também falas em que aparecem uma sobrecarga emocional com estressores e sentimentos negativos que impediram as gestantes de vivenciarem a gravidez da maneira idealizada por elas. Outros achados que também merecem destaque nesse estudo são os relatos de incerteza sobre a continuidade da gravidez, porém a garantia dos profissionais de saúde sobre o baixo risco da transmissão vertical com a adesão da TARV encorajou as mulheres a abandonar os pensamentos negativos.

Os estudos primários selecionados para esta revisão mostram que as mulheres se sentem motivadas a aderir ao tratamento com antirretroviral pensando na saúde dos bebês, entretanto existe o medo de que eles sejam afetados por algum tipo de efeito colateral ou reação adversa grave por conta das medicações. O tratamento, com ARV, é garantido pelo governo brasileiro que distribui esses medicamentos no âmbito do Sistema Único de Saúde (SUS). O acesso à TARV possibilita maior sobrevida e qualidade de vida às pessoas que vivem com HIV. "A terapia antirretroviral diminui significativamente a quantidade de HIV no sangue, suprimindo a carga viral a níveis indetectáveis” (Brasil, 2018)

De acordo com Brasil (2018), apesar de ser inquestionável o benefício da profilaxia da transmissão vertical com o uso de ARV, contribuindo para a prevenção da infecção pelo HIV na criança, podem ocorrer alguns efeitos adversos, sejam maternos durante a gestação ou na profilaxia ao nascimento. O uso desses medicamentos também está associado a um maior risco de prematuridade, risco esse que já existe por conta do vírus do HIV. Leite, Kretzer, Traebert e Nunes (2019)destacam que alguns estudos correlacionam a infecção pelo HIV com o Trabalho de Parto Prematuro (TPP), e também com o nascimento de crianças com baixo peso pela restrição do crescimento fetal.

Tanto na gestação como no pós-parto, os estudos mostram que o impacto do diagnóstico repercute de forma negativa na vida das mulheres e é um peso que afeta o emocional. De acordo com Mesquita et al. (2019), amamentar é o ato mais pleno e mais sublime de uma mãe, pois nesse momento ela compartilha com o filho sentimentos de amor e carinho, passa confiança e divide aconchego, laços que fortalecem o vínculo entre eles. Sendo assim, compreende-se que não amamentar pode representar uma barreira na construção desse vínculo, e esta afirmação foi encontrada nos seguintes estudos (Spindola et al., 2015; Willcocks et al.,2016; Pinto et., 2017).

Alvarenga et al. (2019), destacam em seu estudo que não poder amamentar foi considerado pelas mães o momento mais difícil da trajetória de cuidado à criança exposta ao HIV, e o relato de sofrimento diante desta impossibilidade foi unânime entre aquelas que tinham ou não amamentado previamente outro filho.

O fato de a mãe não amamentar também implica em outras questões que aparecem nos estudos selecionados para esta revisão. Segundo Pinto et al. (2017), várias mães relataram além de receio em relação à qualidade do vínculo, preocupação com o desenvolvimento do bebê e incompletude da maternidade. McLeish e Redshaw (2016), abordam em seu estudo a luta das mulheres para manter a identidade materna e a necessidade de mentir sobre o porquê de não estarem amamentando, devido ao medo de terem a condição sorológica descoberta e sofrerem preconceito. Spindola et al. (2015), também trazem relatos de mulheres que sofrem ao serem questionadas por não estarem amamentando. Segundo Alvarenga et al. (2019) as mães abandonam o sonho de amamentar para proteger os filhos e tentam amenizar o impacto emocional com o apoio de alguns familiares e mediante o afastamento físico da criança.

Spindola et al. (2015), afirmam que estudos internacionais têm apontado que a amamentação não está sendo mais contraindicada, desde que a mãe e a criança usem a TARV durante todo o período da lactação. As justificativas apontadas para esta medida seriam os benefícios do leite materno para o fortalecimento do sistema imune, a prevenção da desnutrição e das doenças diarreicas e respiratórias. Os índices de mortalidade no primeiro ano de vida e a dificuldade de aquisição das fórmulas lácteas e água potável também aparecem como justificativa para tal medida. Entretanto o próprio estudo deixa claro que esta 
aplicabilidade é controversa, cabendo às autoridades nacionais decidirem sobre o melhor método. De fato, "No Brasil, realizase o aconselhamento para as mães que vivem com HIV sobre a não amamentação e uso da fórmula láctea infantil disponibilizada gratuitamente pelo Sistema Único de Saúde (SUS) é garantida pela Portaria GM/MS n. 2.313 de 19 de dezembro de 2002" (Alvarenga et al., 2019).

Segundo Brasil (2018), os Protocolos Clínicos e Diretrizes Terapêuticas para HIV recomendam a não amamentação nos casos de mulheres com HIV, já que esse vírus pode ser transmitido ao bebê através do leite materno. Ressalta-se ainda que mesmo que as mulheres estejam em tratamento e tenham atingido a CV indetectável, estudos recentes indicam que há possibilidade de transmissão do vírus durante a amamentação. Além do fato de não estarem amamentando, o medo da transmissão vertical também aparece nos estudos analisados como algo que compromete o vínculo. Os estudos da coleta de dados desta revisão que abordam o medo da transmissão vertical são: (Willcocks et al.,2016; Pinto et al., 2017; Payán., 2019; Hernandes et al., 2019; Pacheco et al., 2019). Willcocks et al. (2016) apontam nos relatos de algumas mães a diminuição do contato físico entre elas e seus bebês ocasionada por preocupações com o potencial de transmissão vertical, em algumas falas as mães expressam limitações como restrições de beijos e abraços e a desconfiança de qualquer contato da saliva com o bebê.

No estudo de Willcocks et al. (2016), a questão das barreiras no vínculo entre as mães e os bebês aparece como algo que foi superado com o passar do tempo. Os autores afirmam que algumas mães desenvolveram um vínculo fortalecido, principalmente após os primeiros 18 meses, e uma das razões da melhora no relacionamento materno seria a empatia e a sensação de experiência compartilhada, por seus bebês também terem passado por intervenções como realização de exames e uso de medicações. Outra razão para o vínculo fortalecido parecia ser a consciência materna do distanciamento precoce do bebê que as levou a esforços concertados subsequentes para compensar essas deficiências.

A falta de apoio do parceiro também é um obstáculo enfrentado pelas mulheres diagnosticadas com HIV. Segundo Andrade e Iriart (2015), a realização dos testes rápidos no pré-natal para as gestantes faz com que muitas delas descubram a soropositividade para o HIV durante este período. Em muitos casos, os parceiros, que desconhecem seu próprio estado sorológico, passam a culpabilizar e discriminar suas mulheres, acusando-as de serem as responsáveis pela contaminação. Alguns dos estudos que compõem esta revisão, bem como outros estudos mostram situações de violência, abuso e fim de relacionamento que são vivenciadas por mulheres após contarem sobre a soropositividade para o HIV. Deste modo, essas mulheres muitas vezes terão que vivenciar sozinhas momentos em que seria importante a presença de seus parceiros.

Outra questão importante que merece destaque é a ansiedade gerada pela espera do diagnóstico da criança. Segundo Brasil (2019), a detecção de anticorpos anti-HIV não é suficiente para o diagnóstico em crianças menores de 18 meses, pois a passagem transplacentária de anticorpos maternos do tipo IgG anti-HIV, principalmente no terceiro trimestre de gestação, interfere no diagnóstico. Esses anticorpos maternos podem persistir até os 18 meses de idade, sendo então necessária a realização de testes que detectem o material genético do vírus, como a quantificação da CV. Deste modo, todas as crianças expostas e devem realizar sorologia para o HIV após 18 meses de idade.

Alguns dos estudos selecionados para compor esta revisão trazem relatos referentes à espera do diagnóstico da criança, sendo esta fase um momento em que para algumas mulheres relatam terem esperança de que a criança não seja diagnosticada com o HIV, porém algumas delas preferem não criar expectativas por medo de sofrerem com um resultado positivo. Estes relatos são encontrados nos seguintes estudos: (Spindola et al., 2015; Willcocks et al., 2016).

Hernandes et al. (2019), apontam em seu estudo que para a maioria das gestantes soropositivas, ter um filho saudável seria uma motivação para prosseguirem com o tratamento, e a confirmação do diagnóstico do bebê negativo para o HIV as isentaria do sentimento de culpa. Neste contexto, Pacheco et al. (2019) destacam em seu estudo que uma grande parte das mães que descobriram a contaminação por HIV durante o pré-natal ou na realização do teste rápido na maternidade antes do parto, não realizaram o tratamento, e o recebimento do diagnóstico da criança foi difícil gerando o sentimento de culpa. Os autores 
destacam ainda que o diagnóstico da mãe nem sempre é descoberto em tempo oportuno para que se possa evitar a TV ou, em raros casos, as mães não são orientadas da forma correta para tomarem todas as medidas de prevenção. Logo, fica evidente a importância dos profissionais de saúde na prestação dos cuidados necessários para alcançar os resultados esperados.

\subsection{O papel dos profissionais de saúde na assistência às gestantes e puérperas diagnosticadas com o HIV}

De acordo com Araújo, Quirino, Pinho e Andrade (2018), o impacto do diagnóstico do HIV costuma ser intenso não só para quem recebe o resultado positivo, mas também para o profissional de saúde. Ainda segundo os autores, os testes rápidos são realizados pelos enfermeiros e estes relatam dificuldades no momento da revelação do diagnóstico e aconselhamento, principalmente para lidar com a reação dos usuários diante do resultado positivo.

Como já foi discutido anteriormente, a descoberta do diagnóstico do HIV na gestação ou pós-parto repercute de forma negativa na vida das mulheres e os efeitos desse diagnóstico foram observados nos estudos e descritos como sendo algo impactante que necessitam de acompanhamento e de intervenções adequadas levando-se em consideração todos os aspectos que envolvem a maternidade. Segundo Alencar (2018), a luta contra a AIDS e os danos provocados por esta Síndrome representam um dos grandes desafios no campo da saúde. Os autores destacam também que na gestação os riscos e agravantes associados ao HIV são maiores por se tratar de um momento em que a mulher está mais frágil e precisará enfrentar a sociedade, o medo de ser criticada e o medo da TV. Deste modo, entende-se que a mulher na condição de gestante ou puérpera precisa de uma assistência diferenciada e deve ser encorajada a exercer o papel de mãe e de se cuidar para que possa também cuidar da criança.

Rahim, Gabatz, Soares, Milbrath e Schwartz (2017), apontam o autocuidado no ciclo gravídico-puerperal como sendo um dos enfoques das linhas de cuidado à saúde da mulher nas políticas de saúde brasileiras e destacam a importância da assistência ao pré-natal, sobretudo para mulheres em condições crônicas de saúde, as quais se enquadram as mulheres diagnosticadas com o HIV.

Em todos os estudos selecionados para esta revisão de literatura é indiscutível a importância do profissional de saúde na assistência às gestantes e puérperas diagnosticadas com o HIV. Entretanto, alguns dos estudos destacam pontos negativos ou questões que precisam ser melhoradas. Sendo assim, nesta sessão serão abordados aspectos positivos e negativos abordados nos estudos analisados bem como as sugestões e propostas apontadas nos referidos estudos para a melhora na assistência prestada às mulheres diagnosticadas com o HIV.

Em seis dos estudos selecionados destaca-se a qualidade da assistência prestada pelos profissionais de saúde às mulheres diagnosticadas com o HIV, sendo esta assistência fundamental na adesão ao tratamento e em alguns casos na melhor aceitação do diagnóstico, motivação e melhor enfrentamento dos impactos e efeitos causados pelo diagnóstico positivo. (Spindola et al., 2015; McLeish \& Redshaw, 2016; Willcocks et al.,2016; Payán et al., 2019; Hernandes et al., 2019; Souza et al., 2019).

Spindola et al. (2015), destacam a importância da equipe multiprofissional na assistência à gestante com o HIV e ressaltam também a contribuição da enfermagem na educação em saúde, promoção do autocuidado e acompanhamento nas consultas de pré-natal e puericultura.

Alguns dos estudos desta revisão apontam pontos negativos encontrados nas falas das mulheres em relação ao atendimento recebido pelos profissionais de saúde. Esses relatos foram encontrados nos seguintes estudos: (McLeish \& Redshaw, 2016; Willcocks et al., 2016; Medeiros \& Jorge, 2018; Payán et al., 2019).

McLeish e Redshaw (2016) trazem em seus estudos relatos em que os profissionais de saúde de alguma forma subestimaram as implicações do diagnóstico do HIV. Em algumas falas, as mulheres relatam terem recebido bons cuidados pré-natais, entretanto, elas afirmam que sentiram lacunas nas informações prestadas pelos profissionais ocasionadas pela 
pressão por causa do tempo e por muitos não entenderem a situação na perspectiva de uma mãe. Willcocks et al. (2016) trazem relatos onde algumas mães afirmam que perceberam um potencial significativo de discriminação dos profissionais de saúde com os seus bebês por conta da soropositividade materna. Já Medeiros e Jorge (2018) fazem uma crítica à assistência prestada com o intuito apenas de seguir as normas protocolares das redes formais. Para os autores neste tipo de assistência pode-se exercer uma violência.

No estudo de Payán et al. (2019) aparece um relato onde o profissional de saúde juntamente com a mãe da gestante diagnosticada com o HIV, a encorajaram a abortar. Este relato demonstra despreparo profissional, desconhecimento e falta de ética.

De um modo geral, percebe-se nos estudos analisados que nem todas as instituições de saúde e nem todos os profissionais estão preparados para prestar uma assistência adequada às mulheres diagnosticadas com o HIV. Percebe-se em alguns estudos que as mulheres passam por situações de sofrimentos emocionais que poderiam ser amenizados com a intervenção dos profissionais de saúde. De acordo com Guimarães et al. (2019), no caso das puérperas, é preciso que os profissionais de saúde estejam atentos para observar possíveis variações de humor como, reações depressivas e o medo de enfrentar o preconceito das pessoas. Os autores destacam ainda que grande parte dos profissionais não está pronta para realizar um aconselhamento individual ou coletivo de qualidade às puérperas. Além disso, as puérperas com HIV no alojamento irão se sentir excluídas por verem outras mães amamentando seus bebês e elas não poderem fazer o mesmo.

De acordo com Brito, Pôrto, Sousa, Neto e Silva (2017), o tratamento do HIV exige dos profissionais de saúde compromisso, responsabilidade e planejamento da assistência, de forma efetiva e organizada. Ainda segundo os autores, o enfermeiro deve avaliar e planejar intervenções de acordo com a necessidade de cada paciente. Neste contexto, a religiosidade também tem um papel importante e é considerada como um fator de proteção e de enfrentamento do diagnóstico do HIV.

Souza et al., (2019) apontam a religião, a fé e a confiança em Deus como suporte emocional no enfrentamento do diagnóstico do HIV e esperança de dias melhores. Os autores também destacam a educação em saúde, sendo esta uma ferramenta utilizada pela enfermagem com o objetivo de minimizar os efeitos colaterais dos medicamentos e promover melhor qualidade de vida.

Nos estudos de Hernandes et al. (2019) e Pacheco et al. (2019) a educação em saúde também aparece, sendo citada pelos autores por sua importância, onde fica clara a necessidade de que esta aconteça desde o pré-natal, sendo ela um dos pilares do fazer da enfermagem.

De acordo com, Santos et al. (2020), a educação em saúde através da consulta coletiva realizada nos grupos de gestantes possibilita às participantes uma fonte de apoio e encorajamento além de proporcionar a aprendizagem de novas maneiras de lidar com o HIV. Segundo Guimarães et al. (2019),as ações educativas com gestantes e com puérperas devem ser implementadas no sentido de diminuir o constrangimento da mulher em relação à sua condição. Ainda segundo os autores, deve-se levar em conta as particularidades, angústias, conflitos e dúvidas a fim de reduzir a ansiedade dessas mulheres.

Payán et al. (2019) em seu estudo apontam que os grupos de apoio e aconselhamento para indivíduos recémdiagnosticados é um mecanismo potencial para aumentar os níveis de apoio social para Pessoa Vivendo com HIV (PVHIV) além de fornecer informações e instruções sobre o tratamento. Os autores também apontam os grupos de apoio como sendo capazes de proporcionar motivação, enfrentamento positivo, incentivo e interação com outrasPVHIV.

Em sete dos onze estudos selecionados para esta revisão de literatura, aparecem sugestões para melhorias na assistência às mulheres diagnosticadas com o HIV. Sendo estes: (Spindola et al., 2015; Faria \& Piccinini, 2015; McLeish \& Redshaw, 2016; Lingen-Stallard et al., 2016; Pinto et al., 2017; Hernandes et al., 2019; Pacheco et al., 2019).

Spindola et al. (2015) destacam a importância da assistência humanizada com escuta das gestantes que vivem com HIV a fim de compreender o abstratismo das percepções, sentimentos e significados que estas trazem sobre suas vidas. Os 
autores abordam ainda a importância da construção do vínculo tendo como finalidade facilitar ao profissional de saúde uma comunicação eficaz, a realização de práticas de cuidado e promoção da qualidade de vida.

Faria e Piccinini (2015), apontam a necessidade de ampliação do foco na assistência para além da transmissão vertical, com atenção especial à saúde mental materna com o intuito de proteger a criança em desenvolvimento. Para os autores tal assistência consiste também em compreender questões sociais que envolvem o estigma e diversas barreiras às quais as mães estão sujeitas, a fim de auxiliá-las a encontrar apoio familiar além de promover a autonomia e a busca pelos seus direitos. Neste contexto, Pinto et al. (2017) sugerem que os profissionais de saúde devem empregar estratégias para manter a adesão ao tratamento da TV antes e após o parto com ênfase nas questões relacionadas à gravidez/maternidade.

McLeish e Redsha, (2016) em seu estudo destacam o significado e o impacto emocional do apoio da Mãe Mentora durante a gravidez. Sendo este apoio um suporte fundamental também para o desenvolvimento da criança que pode sofrer consequências negativas e duradouras no desenvolvimento físico, psicológico, mental e emocional, ocasionados pela depressão e estresse da mãe na gestação ou após o parto. Já Lingen-Stallard et al. (2016) sugerem que as parteiras devem ser mais bem treinadas para apoiar as mulheres diagnosticadas com HIV e fornecer suporte individual, manter confidencialidade e informações precisas.

\section{Conclusão}

Esta revisão integrativa de literatura teve como objetivo sintetizar o conhecimento produzido na literatura científica nos últimos cinco anos (2015 a 2020) acerca do impacto do diagnóstico do HIV na gravidez ou pós-parto e seus efeitos na vida das mulheres.

A análise dos estudos selecionados possibilitou uma reflexão sobre os aspectos emocionais, psicológicos e sociais das gestantes e puérperas que são diretamente afetados com a descoberta da soropositividade e através dos resultados encontrados, foi possível dimensionar a complexidade dos efeitos causados pelo diagnóstico do HIV na vida das mulheres e identificar a necessidade de intervenções capazes de minimizar tais efeitos. Observou-se também importância da equipe multidisciplinar e de um acompanhamento com ênfase nas questões emocionais relacionadas ou não à maternidade, a fim de proteger a criança não só da transmissão vertical, mas de possíveis prejuízos no seu desenvolvimento, relacionados à depressão ou outras complicações psicológicas sofridas por suas mães. Destaca-se o papel da enfermagem no aconselhamento pré e pós teste rápido, acolhimento, incentivo na adesão ao tratamento e na educação em saúde principalmente durante o pré-natal.

Esta revisão de literatura reforça a necessidade de mais trabalhos que abordem as implicações da descoberta do HIV na gestação ou pós-parto e que possibilitem a compreensão dos profissionais de saúde acerca de tais implicações para que se possa traçar estratégias para minimizá-las.

Espera-se que este estudo possa despertar o interesse pelo tema abordado, para que sejam desenvolvidos trabalhos e também ações que possam contribuir para a promoção da saúde das mulheres diagnosticadas com o HIV nas Unidades Básicas de Saúde (UBSs)ou maternidades através de intervenções baseadas nas demandas encontradas com o uso de estratégias que atendam às necessidades individuais de cada mulher, que promovam qualidade de vida e possibilitem a ressignificação da vida após o diagnóstico do HIV.

\section{Referências}

Alencar, J. T. (2018). O Atendimento Multiprofissional Ofertado à gestantes HIV + no Núcleo de Assistência Henfil em Palmas TO; Revista Humanidades e Inovação. 5(11)

Andrade, R. G \&Irriart, J. A. B. (2015). Estigma e discriminação: experiências de mulheres HIV positivo nos bairros populares de Maputo, Moçambique; Cad. Saúde Pública, 31(3):565-574. 
Alvarenga, W. A., Nascimento, L, C., L., C. L Fabbro, M. R. C., Bussadori, J. C. C., Melo, S. S. S., Cartagena-Ramos, D., \& Dupas, G. (2019). Mães vivendo com HIV: a substituição do aleitamento por fórmula láctea infantil; Rev. Bras. Enferm. 72(5).

Araújo, E. J., Quirino, E. M. B., Pinho, C. M., Andrade, M. S. (2018). Percepção de enfermeiros executores de teste rápido em Unidades Básicas de Saúde; Rev. Bras. Enferm. 71(1).

Bastos, R. A., Bellini, N. R., Vieira, C. M., Campos, C. J. G., \& Turato, E. R. (2019). Fases psicológicas de gestantes com HIV: estudo qualitativo em hospital. Revista Bioética, 27(2), 281-288.

Brasil, Ministério da Saúde. (2020). Departamento de Doenças de Condições Crônicas e Infecções Sexualmente Transmissíveis.

Brasil, Ministério da Saúde. (2018). Departamento de Vigilância, Prevenção e Controle das IST, do HIV/Aids e das Hepatites Virais, Brasília.

Brasil, Ministério da Saúde. Secretaria de Vigilância em Saúde. (2017). Departamento de Vigilância, Prevenção e Controle das Infecções Sexualmente Transmissíveis, do HIV/Aids e das Hepatites Virais. Cuidado integral às pessoas que vivem com HIV pela Atenção Básica: manual para a equipe multiprofissional. Brasília.

Brasil, Ministério da Saúde, Secretaria de Vigilância em Saúde. (2018). Departamento de Vigilância, Prevenção e Controle das Infecções Sexualmente Transmissíveis, do HIV/Aids e das Hepatites Virais;Protocolo Clínico e Diretrizes Terapêuticas para Manejo da Infecção pelo HIV em Crianças e Adolescentes, Brasília.

Brasil, Ministério da Saúde, Secretaria de Vigilância em Saúde. (2018). Departamento de Doenças de Condições Crônicas e Infecções Sexualmente Transmissíveis; O que você precisa saber sobre o HIV e a amamentação cruzada. Brasília.

Brasil, Ministério da Saúde, Secretaria de Vigilância em Saúde. (2019). Departamento de Doenças de Condições Crônicas e Infecções Sexualmente Transmissíveis, Protocolo Clínico e Diretrizes Terapêuticas para Prevenção da Transmissão Vertical do HIV, Sífilis e Hepatites Virais, Brasília.

Brasil, Ministério da Saúde, Secretaria da Vigilância em Saúde. (2019). Programa Nacional de DST/ Aids. Boletim epidemiológico AIDS/DST. Brasília; 2019. ISSN 15171159 .

BRASIL, Ministério da saúde, Secretaria de Saúde do Distrito Federal. (2018). Sociedade Brasileira de Infectologia;Brasil.

Brito, J. L. O. P., Pôrto, S. C. A, Sousa, M. J. F., Neto, V. L. S., Silva, R. A R. (2017). Diagnósticos, Intervenções e Resu ltados Esperados de Enfermagem para Pacientes com HIV/Aids: Revisão Integrativa. Revista Brasileira de Ciências da Saúde. Volume 21 Número 2 Páginas 165-172 2017. ISSN 1415-2177

Domingues, R. M. S. M., Saraceni, \& Leal, M. C. (2018). Notificação da infecção pelo HIV em gestantes: estimativas a partir de um estudo nacional;Rev Saúde Pública.

Faria, E. R., \& Piccinini, C. A. (2015). Representações maternas no contexto do HIV: gestação ao segundo ano da criança.Psicologia Em Estudo, 20(4), 625637.

Fernandes, P. K. R. S., Miranda, D. P. R., \& Vasconcelos, L. D. P. G., Revelação diagnóstica para o HIV no pré-natal: dificuldades e estratégias de enfrentamento das mulheres; Revenferm UERJ, Rio de Janeiro, 2017; 25:e12114.

Guimarães, J. V., Martins, M. D., Cruz, S. S., \& Guimarães, M. R, (2019). Assistência do enfermeiro obstetra à puérpera com HIV em alojamento conjunto. São Paulo: Revista Recien. 2019; 9(28):37-43.

Hernandes, C. P., Rocha, R. K., Hausmann, A., Appelt, J. B., \& Marques, C. M (2019). Análise qualitativa dos sentimentos e conhecimentos acerca da gestação e do HIV em gestantes soropositivas e soronegativas / Qualitative analysis of feelings and knowledge'sabout pregnancy and HIV in seropositive and seronegative pregnant women. J. Health Biol. Sci. (Online).

Leite, T. L. S., Kretzer, M., Traebert, J., \& Nunes, R. D. (2019). HIV na gestação: pré-natal, parto e puerpério; Ciências \& Saúde.

Lingen-Stallard A., Furber. C. \& Lavender, T. (2016). Testing HIV positive in pregnancy: A phenomenological study of women's experie nces. Midwifery. $35: 31-8$

Leite, K., \& Traebert, N. (2019). Fatores Associados à Prematuridade em Gestantes Portadoras do Vírus HIV em um Estado do sul do Brasil; Arq. Catarin Med.

Lewandowski. D. C., Camavarro, M. C., Pereira, M. D., Maia, G. N., Schuck, L. M., Sanches, I. R. (2017). Maternidade e HIV: revisão da literatura brasileira (2000-2014). Arq. bras. psicol. 69(2).

Lima, S. S., Silva, L. C. S., Santos, M. V., Martins, J. P., Oliveira, M. C., Brasileiro, M. E. (2017) HIV na gestação: pré-natal, parto e puerpério; Ciências \& Saúde

Lôbo, A. L. S. F., Santos, A. A. P., Pinto, L. M. T. R., Pinto, L. M. R, Rodriguês, S. T. C., Barros, L. J. D., Lima, M. G. T. (2018). Representações sociais de mulheres frente a descoberta do diagnóstico do HIV. Rev Fund Care Online.

McLeish J, \& Redshaw, M. (2016). We have beaten HIV a bit': a qualitative study of experiences of peer support during pregnancy with an HIV Mentor Mother project in England. BMJ Open.

Medeiros, D. S., \& Jorge, M. S. B. (2018). A invenção da vida na gestação: viver com HIV/aids e a produção do cuidado; Sex., Salud Soc. (Rio J.) no.30 Rio de Janeiro. 
Mesquita E. B. S., Maia, N. M.F. S., Mesquista, E. B. S., Santos, E. B., Silva, M. G., Fonseca M. V. S., Pereira, L. B. M., Mesquita, A. B. S. Oliveira, A. F. S., \& Brito, C. A. R. S. (2019). Sentimentos de mães com HIV frente a não amamentação; Atena Editora.

Oliveira, A. D. F., Vieira, M. C. A., Silva, S. P. C., Mistura, C., Jacobi, C, S., \& Lira, M. O. S. C., Repercussões do HIV no cotidiano de mulheres vivendo com AID; J. res.: fundam. care. online 2015. 7(1):1975-1986.

Pacheco, B. P., Nobre, C. M. G., Costa, A. R., Nornberg, P. K. O., Medeiros, S. P., Gomes, G. C. (2019). Síndrome da imunodeficiência humana na criança: repercussões para a família / Humanimmunodeficiencysyndrome in children: repercussions for the family; Rev. enferm. UFPE on line; 13 (1): 15-22.

Pereira, A. S., Shtsuka D. M., Parreira, F. J., \& Shitsuka, R. (2018). Metodologia da Pesquisa Científica, UFSM.

Payán, D. D., Derose K.P., Fulcar M. A., Farías, H., \& Palar, K. (2019). "It Was as Though My Spirit Left, Like They Killed Me”: The Disruptive Impact of an HIV-Positive Diagnosis among Women in the Dominican Republic.

Pinto, M. D., Maia, G. N., Pereira, M D., \& Levandowski, D. C. (2017). Mães adolescentes que vivem com o HIV: uma investigação qualitativa sobre a "Constelação da Maternidade". Psicol. clin. 29(3).

Renesto, H. M. F., Falbo, A. R., Souza, E., \& Vasconcelos, M. G. (2014). Enfrentamento e percepção da mulher em relação à infecção pelo HIV; Rev Saúde Pública.

Rahim, S. H., Gabatz, R. I. B., Soares, T. M. S., Milbrath, V. M \& Schwartz, E. (2017). Gestantes e puérperas soropositivas para o hiv e suas interfaces de cuidado. Revenferm UFPE on line., Recife, 11(10):4056-64.

Santos, K. L., Rodrigues, S. T. C., Santos, A. A. P., Sanches, M. E. T. L, Lucena, T. S., \& Vieira, M. J. O. (2020). Transmissão vertical do HIV em gestantes: consulta coletiva como estratégia para redução; Braz. J. of Develop, Curitiba, 6(9), 66920-66931.

Silva, A. N., Santos, A. M. G., Cortez, E. A., \& Cordeiro, B. C. (2015). A família como rede de apoio às pessoas que vivem com HIV/AIDS: uma revisão na literatura brasileira; Ciênc. saúde coletiva. 20(4).

Silva, C. M., Alves, R. S., Santos, T. S., Bragagnollo, G. R., Tavares, C. M., \& Santos, A. A. P. (2018). Panorama epidemioló gico do HIV/aids em gestantes de um estado do Nordeste brasileiro. Revista Brasileira de Enfermagem.

Souza, F. L. P., Clark, L. M., Lelis, B. D. B., Dusso, M. I. S., \& Leite, A. M. (2019). Sentimentos e significados: HIV na impossibilidade de amamentar / Feelings and meanings: HIV in the impossibility of breastfeeding; Rev. enferm. UFPE on line; 13: [1-7].

Spindola, T., Dantas, K. T. B., Cadavez, N. F. V., Fonte, V. R. F. D., \& Oliveira, D. C. (2015). Maternity perception by pregnant women living with HIV. Invest. educ. Enferm. 33(3).

Tostes, M. F. P \& Galvão, C. M. (2019). Implementationprocess of the surgicalsafaty checklist: integrativa review. Rev. Latino-Am. Enfermagem. 27(3104).

Willcocks, K., Evangeli, M., Anderson, J., Zetler, S., \&Scourse, R. (2016). I Owe Her So Much; Without Her I Would Be Dead \&quot: Developing a Model of Mother-Infant Bonding Following a Maternal Antenatal HIV Diagnosis; J Assoc Nurses AIDS care. 